\title{
An Investigation Social - Economic Status, Organizational Commitment and Occupational Burnout in School Teachers' City of Rasht
}

\author{
Maryam Eslamdost
}

\author{
MSc in Physical Education, Gilan University, Gilan, Iran \\ Elham Mirjamali \\ Corresponding Author, Department of Physical Education \& Sport Sciences, \\ Anzali Branch ,Islamic Azad University \\ Maryam Yousefi
}

MSc in physical education, Shomal university, Amol, Iran

Mohamadreza Abedimahzoun

Faculty of Management and Accounting, Islamic Azad University (IAU), Qazvin, Iran

Doi:10.5901/mjss.2014.v5n23p2684

\section{Abstract}

The purpose of this study was to investigate social - economic status, organizational commitment and school teachers' job burnout of city of Rasht. From 2596 teachers, 503 were chosen randomly by the Social economic source Surveys (SES), organizational commitment (OCQ) and Job exhaustion (MBI)in the researcher's presence in schools for $15-20$ minutes. Research data were analyzed by using Spearman correlation coefficient and in the level of ( $p \leq 0 / 05)$ and $(p \leq 0 / 01)$. Describe of the results showed that organizational commitment of teachers was in high level (83.28 11.34), and the rate of burnout was

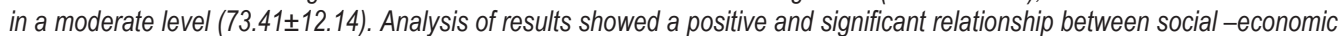
situation and organizational commitment $(R=0 / 618)$. A negative and significant relationship between social - economic situation with teacher burnout $(R=-0 / 68)$. Thus, from among individual characteristics, correlation of age with organizational commitment was positive and significant and with teachers job exhaustion, it was negative and significant. It can be expected that with improving teachers' economic and social situation, pledged to increase their organizational, exhaustion job reduction and increasing the age (along with service record) their commitment will be high and job exhaustion will be low. Attention to the socio - economic status of teachers to increase organizational commitment and burnout in young teachers with low record is important.

Keywords: organizational commitment, the recess, teachers, social- economic status.

\section{Introduction}

One of most important attitude towards work and organization is organizational and job commitment. From Friedman's viewpoint (2000) organizational commitment is essential for the success, efficiency and effectiveness of the organization. Commitment can also cause employees to be more effort and interest (Sabaghian and Stenographer., 2007). In general, committed have more discipline and orders in their jobs, they stay more time for doing more work in the organization (Hamidi., 2008). Research results show that the commitment to the organization can cause the high level of knowledge goals and values of the organization, and a strong desire and willingness to try to stay in the organization and an extraordinary effort for the organization (Garland et al., 2009). The personnel committed is said to employees that they feel commitment not only to individuals and organizations, but to the social groups and different affiliated organizations with an organization for which they work and have a sense of commitment to customers and clients (Schepman et al., 2008). The ideal consequences has put forward due to the commitment of the organization in the individual included, feeling belong to and dependence, security, and the positive imagine of himself in individual and or in the group, membership stability, solidarity and unity and at the end, in the organization level including individual efforts, leaving reduction in service, a decrease in absence, reducing delay (Hamidi., 2004). As well, Organizational commitment may be 
effective on the workplace stress and job exhaustion (Henkin and Holliman, 2009).

Different definitions of organizational commitment have been divided (Lampart et al., 2008). Organizational commitment to both active and independent, or is divided into two Behavioral and Attitudinal commitment (Griffin et al., 2005). In general, organizational commitment is defined as a psychological attachment, the organization's efforts, and having a strong desire to stay and participation in the organization (Garland et al., 2009).At Smith and Mear and Alean's viewpoint (1993) commitment has a three dimensions of commitment, Affective commitment, Continuous commitment, Normative commitment that attitudinal commitment is one of the prominent and distinguished anticipant of behavioral commitment (Heley., 2003). Finally, Han (2007), organizational commitment has divided to the three dimensions of affective commitment, continuous and intellectual commitment and normative or moral commitment. Affective commitment is defined as effective or emotional continuity with the organization and love the job, so that the person enjoys being with the organization's members (Han, 2007).

Continuous commitment is related to be aware of the costs of associated with leaving the organization. Employees with the commitment stay in the organization, because they need such a job and accept its responsibilities. In other words, the person due to compare the cost of leaving the organization, guarantees the obligation of staying in the organization (Srinivas., 1994). In normative commitment, the people through internalizing the goals and values and organization's commissions depend on it and they feel the sense of duty and obligation to stay in the organization (Dee et al., 2006). The common point in all three dimensions of commitment is that the commitment is a psychological expression that it clarifies the relations of the employee with the organization and determines continuity or cut the person's membership in the organization (Hamidi., 2004).

One of the variables associated with organizational commitment is Job burnout. Burnout is a consequence of job stress and it can result in severe stress. Emotional exhaustion is the first and most important dimension of the burnout that has an outstanding relationship with the work pressure (Asuman., 2004).Analysis personal characteristics is also related to the teacher's response of non-emotional and violent behaviors compared to the students, colleagues and clients. The person has a negative attitude and emotions along with others' blame and understands the people in the form of a non-human object. Finally in the reduction of individual success, the teacher feels that he can't be able to show the past deserve and success in his work (Ozdemir., 2008). NIOSH, National Institute of occupational safety and health, according to the amount of stress, is introduced the teachers' job as one of the Thirteen jobs with the levels of high stress. Teachers are main part of the education force and training soldiers that are faced with numerous stressors (Gharaainee and Abbaaszadeh., 2009). On the other hand, job burnout is common among the jobs that deal with human services. Teaching is also one of the same jobs. Job burnout can be serious consequences for the health of teachers and students' learning results and have damage to the quality of teaching. It can also lead to job dissatisfaction, occupational alienation, physical illness, mental, and leaving the teaching profession (Ramzaninezhad et al., 2009). Hy-Sockei and et al (2001), have defined the burnout as suffering from physical conditions related to work due to long-term working, it causes fatigue, weakness, extreme exhaustion on the teachers(Maslach et al., 2001). The student behavior effects on the teachers' burnout and also the teachers' burnout have negative effects on teacher, students, and the school. The teachers' burnout can make the pupils to be bad-tempered inside and outside the school and these changes will have negative effects on the school (Loonstra et al., 2009). Stating that when the teachers have not necessary resources for effective management of social and emotional challenges in their classes, for that reason, the students also show lower taking responsibility and poor performance and behavior from themselves (Griffin et al., 2005). Hogan et al (2006)expressed when the teacher doesn't be responsible for the teaching and also when he doesn't have any responsibility for the teaching methods and contents of the subjects that he teaches students in the class and he doesn't care to correct relations with them, consequently, learning problems among students will increase (Hogan et al.,2007).Without doubt most of the teachers after graduating, go into education with a series of ideals, and learned skills and with regard to the individual differences Orin work environment issues they get into job stress that have a lot of damages and expenses for teachers and the organization (Ursua., 2005). On the other hand, it has a negative impact on the students' performance. Meanwhile, the factors as socio-economic conditions are so determinant and can effect on people's commitment and it's very important factor in determining the job commitment and burnout (chuo., 2003). Therefore, in this study, has been tried to find the relation of the social - economic status and organizational commitment of the Physical and non-physical education teachers' Job burnout (Tumkaya., 2001).

Studies have shown that many teachers experience the signs of the Job burnout in their jobs. McGowan's Research (1984), showed that nearly 25 percent of the teachers at Queensland, in Australia, have experienced stress and exhaustion (Ramzaninezhad et al., 2009). The rates of teachers' decrease in the United States have been reported from $6 / 5 \%$ in the year 1988 to $4 / 7 \%$ in the year 2000. Recent statistics show that almost a third teachers in their first 5 years of teaching leave their jobs. 50 percent rate of reduction in high school teachers, 42 percent in guidance teachers 
and 36 percent in elementary school teachers, shows that they have no tendency to teach until the year 2010 in the schools (Pandey and Tripathis., 2001) reported that in The UK annually about 5 billion pounds and in the United States approximately 77 billion dollars from this way the industries have damaged ( Cheek et al., 2003). Common studies in health professions have shown that the amount of exhaustion is between 30 to 47 percent. Despite the fact, the amount of exhaustion in retired employees in Brazil is about 10 percent (Brouwers and Tomic.,1999). The research shows that more than 20 percent of the teachers have been suffered Job burnout due to the differences between the expectations that have in their jobs and the amount of their efforts and reward that receive (Ozdemir., 2008). In the years 1982 to 1994, Only Lee and 1996 with the implementation of six experimental research in this regard showed that organizational commitment with emotional exhaustion and empty the characteristics of individual negative relationship and meaningful (Pandey and Tripathis., 2001)Although relation between organizational commitment with job burnout in Iran in a little research has been checking, but the gap research job in different societies in which completely obvious and more to the link between each of these function" into a separate Varier with the other has been dealt with. study of the relationship with the leadership styles football coaches with the amount of commitment and players ex articulation analysis concluded between commitment and exhaustion players negative relationship and there is a meaningful and increase the amount of exhaustion players commitment they will decrease (Ashrafi et al., 2010 ). In a research as a link between the organizational commitment and exhaustion Physical Education instructor's job public reached the conclusion that organizational commitment in the scientific teachers than private teachers. Only part of emotional commitment can be anticipant analysis ex articulation teachers. The amount of ex articulation analysis scientific committees of the teachers is less than the private teachers. It is possible to the teachers will decrease the amount of analysis has been ex articulation (Sabaghiyanerad and Toondnevis., 2007). Moein's and et al (2010), in the study entrepreneurial communication and organizational commitment with exhaustion on the job Janson's employees Free University Rudhen unit to the conclusion that no meaningful solidarity Organization and the commitment there is a staff Job (Moein's and nazem., 2010). Ashrafi and et al (2010) in study of the relationship with the exhaustion organizational commitment job junior teachers in the town of Mahabaad's on 300 teachers from junior high schools to the conclusion that solidarity and reverse the organizational commitment and exhaustion teachers job there (Ashrafi et al., 2010 ). srinivas (1994), with the approval relation between the organizational commitment and exhaustion of the exhaustion and a decrease in organizational commitment decreased job satisfaction, the increase in his absence and relocation also disturb connection between the members of the group and his colleagues, friends and family even in finally profession teaching pillion (srinivas.,1994). In this regard Cole said Edrish team (1998) showed that commitment may individual against environment protection, and through this reduction exhaustion. With impact of the commitment of the organization ex-articulation analysis Vaziri's works in human services to the conclusion that they will be higher than organizational commitment, wears out less than a job. They said that studies show that unasserted committed an employee in accepting the goals and values and so is his willingness to work for the organization, the desire to join the WTO, in the organization and the workplace, a sense of belonging to the organization and the amount of stress and analysis in less than ex-articulation jobs and health and Michael Ivanovich you more for duties and responsibilities of a job (Ramarajan., 2006).

Research with the past 25 years to the conclusion that the increase in the amount of interest and commitment and commitment to teachers and the Organization of the job can be worn out job stress resulting from a long-term and reduce chronic or absence in work and left their jobs and less physical and mental health them more (chuo.,2003).also showed that the amount of high and absence of a job in exhaustion teachers commitment to at least teacher to the organization, school and is teaching(Lampart et al, 2008). In (2003) showed that much stress long-time can be caused by the occupational exhaustion teachers, reduce bear students and lack of commitment to the teaching profession (Cheek et al., 2003). Chuo (2003) in his thesis study of the relationship with organizational commitment and exhaustion post showed that in comparison with emotional commitments and continuous commitment barking kind anticipant better to emotional exhaustion and depletion of the characteristics of a person (chuo.,2003). Heley (2003) in the thesis that has increased levels of employment and reduces exhaustion organizational commitment there. Prince Nayef also reversed and meaningful success decrease between individual and organizational commitment was seen (Heley., 2003). Chapman (2008) in study of the relationship between ex-articulation analysis and organizational effectiveness and commitment 140 employees in Washington reached the conclusion that ex articulation analysis and negative relationship with a pledge to have an organization (Chapman.,2008). With the effect of job exhaustion teachers in the primary health organization concluded that with interest rates and commitment to exercise teachers to teach the amount of exhaustion can be a job at them (Loonstra et al., 2009, Sabanci., 2009 ). In some studies regard, some important characteristic individual with a pledge to an organization and exhaustion study job. For example, Mathieu and zajac had been with analysis of more than 200 research of that age relationship with a pledge to an organization, positive and meaningful level and with education and negative is meaningful to the conclusion that the gender, age with a pledge educational institution there is no relation 
(Bell- Roundtree,Carolyn V, 2004). in a research on high school teacher 389 us schools, they concluded that the increase in professional experience with a commitment to an organization is negative and defenseless people with higher than the amount of teaching organizational commitment and higher than the exhaustion had a job with the exhaustion 414 job of high school teacher showed that teachers in the single study and teaching record with less than the amount of the higher the exhaustion of a job experience(Kim- Wan Mo,. 1991). Despite this, very little research on relation of the socialeconomic commitment with exhaustion and organizational job has been done. In their research found that social and economic situation is very important factor in determining job commitment and exhaustion (Fejgin,. 2005). These results show that the people who in terms of the social and economic level in a better may have the amount of exhaustion less job experience. Having welfare facilities and services and support resources can be somewhat teacher stress in daily contact with colleagues and reduce organization and a teacher with more comfortable imaginary classroom and in dealing with problems of the students. This has caused to the amount of exhaustion decrease in teacher job

The human forces active in organizations, teachers is very vital role in the growth and development. In the awareness of the factors levels their commitment is very necessary (Razak, 2009). Simon (1990) believes that the commitment is very important factors in the teaching and successful students' impulse, continuous commitment and is very high in the teachers. Commitment a teacher in a key factor in teaching and learning students' ((Ursua., 2005). Teachers who have a high commitment to the teachers who low level of commitment they possess, more positive outlooks caused the spread of the students and increase the efficiency are class ( Sabanci, Ali, 2009, Ozdemir., 2008, Moreira., 1995 ). According to the head of the (1990) commitment is very important factor in the process teaching and learning of the students. Commitment for the high school teacher and better relationship with students and their correlation increase (Garland et al., 2009, Mathew and Shepherd., 2002, Ramarajan., 2006 ).

Of course there have been very little of the juvenile, the results of the behavior of the commitment of an organization like the exhaustion, and study that Conversional dependent on the main research. A little research on effective factors in exhaustion teachers job and is Conversional that it is possible that the exhaustion teachers play a role, pledged their organization. Of course many of the factors juvenile anticipant emphasized organizational commitment and concentration, but the consequences of the Organization of commitment to the organization had been (Friedman, 2000).

Many studies in organizational commitment as variable and independent or as a conversional affiliated to have been. In a review of the background of this issue, by reviewing 33 studies showed that in 11 studies, commitment to an independent conversional in more than 20 studies as variable is dependent on (Hamidi., 2004) extensive investigations in regard to different groups organizational employees, managers, the members of the scientific, teachers and also in the field job exhaustion workers, nurses, librarians are, university lecturers managers, teachers have been done (Asuman., 2004). Despite this, one of the existing weaknesses in the background research related to Job exhaustion and organizational commitment is that more juvenile institutions and medical services, employees, soccer players, teachers University, has been done and a little research on organizational commitment job exhaustion with the teachers in schools (Maslach et al.,2001). So - the status of organizational commitment and exhaustion teachers in a post that real program's programs are education is very important to. With regard to the findings of the contradictory on the status of organizational commitment ex articulation analysis and different jobs, this question comes to Rasht's that teachers in these two variables in how they are? On the other hand, with regard to the nature and characteristics of Physical Education teacher's job still is quite clear that the situation of organizational commitment and exhaustion this job teacher with other teachers in how is it? What is the relationship between commitment and exhaustion organizational job teachers there is a city of Rasht. And do the job commitment and exhaustion in the Physical Education teachers and non-physical education is different. Of course, the nature of relationship between the two-edged sword commitment and exhaustion in research study job; but before assuming the present research is an organization that can be commitment levels exhaustion. It seems that economic conditions-teachers commitment and exhaustion in their job. Therefore such a question that will be formed what is the relationship between the economic and social organization teachers and commitment and exhaustion their job? In response to this question to teachers and Junior high schools to teach at different schools and confrontation with rapid changes and Conversional emotion and social behavior or varieties students with more stress.

\section{Materials and Methods}

The statistical research all the Physical Education teachers and non-physical education and women in the junior high and secondary education city of Rasht, in the academic year 88-87, 39 school in the region 1 and 2 city of Rasht, to work. Physical Education teachers were 134 people. With regard to the small community of statistics all men and women teachers physical education, among the statistical sample research and from this number, 127 people in present research 
company. And the total number of Physical Education teachers for men and women in the region 1 and 2 Rasht Guidance and Secondary schools, 2462 people who were with regard to the table model estimated 379 were among the statistical sample taken into consideration, but considering the possibility s ups problem behaviors, 400 non-physical education teacher in a car accident were elected.

\section{Instruments}

In order to collect information from the three questionnaire economic base-social (SES), pledged (OCQ) and exhaustion (MBI). Questionnaire individual characteristics include secretaries, characteristics of the population of familiarity (eight questions). The second instrument Module, questionnaire organizational commitment and Allen with 24 questions on a scale of 5 value in the (totally disagree) to 5 (totally agree with). By using the coefficient Spectrometer, an internal stability commitment ( $\alpha=0 / 86$ ) was confirmed. The third tools, questionnaire standard exhaustion teachers job. The questionnaire contains 22 question with seven value on a scale of 0 (never) to 6 (always). By using the coefficient Spectrometer, job stability inner exhaustion $(\alpha=0 / 94)$ was confirmed. Then in the main factor of 3 to as the agent of emotional exhaustion with 9 I "Today, the factor of personal success with 8 I "today are empty and the characteristics of a person with $5 \mathrm{I}$ "today were examined. The fourth questionnaire part of the situation of economic and social research (SES) was that teachers with questions as much as 5. Including the level of income, the place of residence, post men, women, education men, women, is measured. Betreffend socio-economic research in social science and sociology is based on the status of social-economic condition. Credit and narrative this questionnaire points classification and the coefficient of variables research by Amir zadeh (2003) and then by Taqí poor (2008), and use have been confirmed. In this research also with internal stability $(a=0 / 78)$ had confirmed. Therefore, in total economic and social situation in etiology with the level of income, the place of residence, education and jobs men and women is measured.

Reading is cross-sectional and past-oriented. With the help of the department of education and training of the city of Rasht questionnaire by the presence of research scholar at the disposal Problem behaviors and in a 25-20 minutes explanation and has been completed. With the use of the table at an estimated model, 503 persons for example, in and therefore probably full participation of some Problem behaviors, the number of 534 questionnaire was distributed among teachers and sug 96 percent of the questionnaire were completed and by researcher and analysis. To determine how the distribution of research and test the software copies 17 methods in theory and analysis to study and compare a description of a description of the statistics and analysis based information research, ex articulation coefficient level in $(p \leq 0 / 05)$ used.

\section{Result}

Describing features of the population Problem behaviors of the latest research showed that most teachers in higher age groups of 30 years. Also 54 percent of people were female teachers and 46 percent of them men. The junior high teachers were 47/96 percent of high school and 54/33 percent of the society research. In my degree in both groups, the highest percentage of sample research related to people and higher degree. The teaching record the highest percent related to people with higher teaching record of 10 years. The results of this research showed that teachers' organizational commitment (82/83 $\pm 11 / 34)$, in a high level and it is the amount of exhaustion $(73 / 41 \pm 12 / 14)$ in an average level. In Table 1, To showed the economic and social situation and organizational commitment teachers' meaningful relationship. Also Relation of the social-economic organization with job burn out to teachers in the Meaningful $(p \leq 0 / 05)$

\begin{tabular}{|c|c|c|}
\hline Variables & Socioeconomic Status & Sig \\
\hline Job burn out & $r=0 / 68^{*}$ & $0 / 004$ \\
\hline Organizational commitment & $r=0 / 618^{*}$ & $0 / 000$ \\
\hline
\end{tabular}

To test the hypothesis of first coefficient which was used with regard to the table and meaningful levels only witness meaningful relationship between the two Conversional meaningful level $(P \leq 0 / 05)$. Findings showed the situation of economic and social organizational commitment and positive relationship and meaningful. This means that whatever the teachers in economic and social situation in the more desirable to be as much as the amount of organizational commitment will increase and To test the theory of second coefficient which was used with regard to the data you table levels and meaningful only witness meaningful relationship between the two Conversional meaningful level ( $\leq \leq 0 / 05)$. Findings showed the situation of economic and social relationship with the exhaustion negative job and meaningful. This means that teachers in the economic and social situation in the more desirable to be as much as the amount of 
exhaustion job will decrease.

In Table 2, there were significant relationship between the organizational commitment and burn out teachers' job.

\begin{tabular}{|c|c|c|}
\hline Variables & Job burn out & Sig \\
\hline Organizational commitment & $\mathrm{r}=-0 / 15^{* *}$ & $0 / 001$ \\
\hline
\end{tabular}

There were significant relationship between the organizational commitment and burn out teachers job. To test the theory of third coefficient which was used with regard to the table and meaningful levels only witness meaningful relationship between the two variables meaningful level $(P \leq 0 / 01)$. Findings showed the organizational commitment and job exarticulation analysis teachers negative relationship and it means 148 a petty crime), in a way that increase the level of organizational commitment, the amount of job burnout teachers was reduced.

In Table 3, there were significant relationships between the organizational dimensions commitment with the dimensions burn out teachers' job

\begin{tabular}{|l|c|c|c|c|}
\hline Dimensions Commitment & Emotional Exhaustion & Depersonalization & Personal Accomplishment & Sig \\
\hline Affective Commitment & $-0 / 364^{* *}$ & $-0 / 283^{* *}$ & $0 / 214^{* *}$ & $0 / 000$ \\
\hline Continuance Commitment & $-0 / 102^{*}$ & $-0 / 072$ & $0 / 115^{*}$ & $0 / 05$ \\
\hline Normative Commitment & $-0 / 267^{* *}$ & $-0 / 171^{* *}$ & $0 / 179^{* *}$ & $0 / 000$ \\
\hline
\end{tabular}

Information table (3), shows that the emotional commitment with emotional exhaustion, heroes personality and negative relationship means you are in the $(P \leq 0 / 01)$. But the emotional commitment with the loss of individual success, positive relationship and have seen. Also the continuous commitment with emotional exhaustion, negative relationship and meaningful and also the continuous commitment with the loss of individual success, relations with positive and meaningful commitment with barking kind emotional exhaustion and heroes character, and negative relationship means you can be seen and lack of success with a positive relationship and meaningful.

In Table 4, there were relationships between the organizational commitment and knowledge population variables teachers in this regard. Also the exhaustion job and population variables knowledge teachers in this regard.

\begin{tabular}{|l|c|c|c|c|c|}
\hline Variables & Age & Sex & Married & Education & Record \\
\hline Organizational commitment & $\mathrm{r}=0 / 067^{*}$ & $\mathrm{r}=-0 / 071$ & $\mathrm{r}=-0 / 094^{*}$ & $\mathrm{r}=-0 / 154^{* *}$ & $\mathrm{r}=-0 / 077$ \\
\hline Job burn out & $\mathrm{r}=-0 / 105^{*}$ & $\mathrm{r}=0 / 004$ & $\mathrm{r}=0 / 057$ & $\mathrm{r}=0 / 158^{* *}$ & $\mathrm{r}=0 / 065$ \\
\hline
\end{tabular}

In order to test the theory coefficient fifth that was used with regard to the table and meaningful levels only witness meaningful relationship between the two Conversional meaningful levels $(P \leq 0 / 01)$, ( $P \leq 0 / 05)$. Findings showed the organizational commitment and positive relationship between age teachers and meaningful, that the organizational commitment and married status and education and negative relationship was meaningful (table 4). In order to test the theory coefficient fifth that was used with regard to the table and meaningful levels only witness meaningful relationship between the two Conversional meaningful levels ( $\mathrm{P} \leq 0 / 01),(\mathrm{P} \leq 0 / 05)$. The research shows that the ex-articulation analysis and teachers age negative relationship and there are, of course the ex-articulation analysis and education teachers' positive relationship and meaningful was and the other functions" with ex -articulation analysis relationship was observed.

\section{Discussion}

The commitment of organizational Problem behaviors of research and power point for educational system is very important and should be satisfactory that teachers with such important Hegria to education and prosperous future country who are engaged in. Of course we have strategies to protect it and a decrease in job levels exhaustion thought. The cross-sectional study of the relationship with the organizational commitment with the status of social and economic teachers was shown that between the two variables positive relationships and there is meaningful. By the findings of the Fejgin (2005), and is completely consistent(Fejgin., 2005) Probably teachers who are committed to that in terms of the social-economic level are in a better life. Of course the need for more extensive research and with regard to a little research in this regard, still cannot be clearly stated that the situation of social-economic can be on the amount of commitment and exhaustion completely job will be effective. Study of the relationship of the social-economic job exhaustion teachers showed that between the two Conversional negative relationships and there is meaningful. The results of the investigations are completely consistent Fejgin(2005),Ozdemir(2008) (Fejgin., 2005., Ozdemir.,2008). So it 
is possible that the people who in terms of the social and economic level in a better; it is possible the amount of exhaustion fewer job experience. As having welfare facilities, services and a source of financial support or family can be somewhat teacher stress in daily contact with colleagues and reduce organization and a teacher with more comfortable imaginary classroom and in dealing with problems of the students' more patient. This has caused to the amount of exhaustion in teacher job decrease. With regard to these relations and important in this research, shows that the situation of social-economic can be very important factor in the process teacher commitment to their jobs and teaching more desirable and more fresh spirit in the schools. Present research results showed that the organizational commitment with the amount of exhaustion in job teachers' negative relationship and it means. The study by the results is completely consistent agreed with the findings of the following investigators:Sabaghiyan Rad (2009),Parsa and Nazem (2010), Ashrafi and et al (2010), Bell-Roundtree (2004), Sabanci (2009), Henkin and Holliman (2009), Chuo (2003), Heley (2003), Ramarajan (2006). Because they concluded that by increasing the amount of organizational commitment ex articulation analysis also will decrease. Of course, this research on different job groups like employees, teachers, Service Employees of service, and teachers have been done, in the case that based on the findings Mathieu and the others, whatever the amount of commitment to the teachers higher than the feeling of responsibility will increase and as much stress and exhaustion in the job too much.

These results with the present research are not in conformity. However, research in the field job exhaustion has shown that whatever the amount of individual commitment to their jobs and in an organization that it is working, increase as the amount of interest and dependence on the job and staying in the organization will increase, the decision of the Organization of the most part, has a better teaching and motivation in higher classes will be, as there was a job exhaustion symptoms (Asuman., 2004, Heley., 2003, Henkin and Holliman., 2009). Since most researches on the negative relationship between the two variables have stressed out. Therefore, one of the factors reduces the amount of ex articulation analysis in teachers; increase the level of commitment in their organization. Like commitment probably up that caused the positive, membership stability, harmony and solidarity in the meantime, through the efforts of the individual will decrease his absence, delay in work, security, and the dependence belonged to the group and the organization.

Relations between dimensions organizational commitment with the dimensions exhaustion post showed that the emotional commitment with exhaustion and empty the characteristics of had relation between negative and meaningful; but the emotional commitment with the loss of individual success The relation a positive and meaningful. These results were completely consistent agreed with the findings of the following investigators: Sabanci (2009), Ramarajan (2006), Chuo(2003. Also the continuous commitment with emotional exhaustion had a negative relationship and meaningful was seen, while the continuous commitment with the loss of individual success shows positive relationship and meaningful. The findings of research results with consistent agreed with the findings of the following investigators: sabanci (2009), Ramarajan (2006), Chuo (2003).Meanwhile between the normative commitment with barking kind emotional exhaustion and empty the characteristics of individual negative relationship and meaningful and with individual success to relation positive and meaningful. Results were consistent agreed with the findings of the following investigators: Sabaghiyan (2009),Sabanci (2009), Ramarajan (2006), Chuo (2003).

According to the principles of the theoretical research findings and different dimensions of the organizational commitment, then emotional commitment and exhaustion dimensions of the job, then emotional exhaustion, the most important criteria in determining commitment and exhaustion are job. so it can be concluded commitment and emotional commitment barking kind can cause before the depletion of individual characteristics and emotional exhaustion. It shows that with increasing emotional commitment and barking kind, the amount of emotional exhaustion and empty the characteristics of individual teachers will decrease. Also with increasing emotional commitment and barking kind, the amount of individual success and increase the amount of continuous commitment in emotional exhaustion teachers is reduced and success in their individual increases. So it seems that the devotion, adherence to the job and friendly relations with colleagues in the workplace teachers, open atmosphere and desirable in school (emotional commitment) and also accepting the laws and regulations, religion and to remain in the (commitment barking kind), a teacher with love and more interested in the teaching profession, higher motive for the better in classrooms. In the emotional exhaustion and empty the characteristics of individual teachers in low and this issue is very important role in reducing occupational exhaustion (Dee et al., 2006).

The results showed that between the age and organizational commitment and positive relationship teachers means. By the findings of the "Agreements with the findings of the following investigators: Hamidi and et al (2004). And with results of the investigations razak (2009), Lampart and et al (2008), Henkin and Holliman (2009). Mathieu and Zajak (1990) showed Organizational commitment with individual age relative solidarity and positive. Older people in the organization are pledged to provide needs of growth and success has been provided for them .At present research also 
experienced individuals were higher commitment and perhaps these people feel with their colleagues in the workplace and school and familiarity are more uninterrupted and by increasing the age of their interest to the organization and staying in the organization and their commitment to the organization will increase (Mathew and Shepherd., 2002). On the other hand, feel the power of his youth to this organization and have left the organization and find new jobs for them is not profitable" and also the social and facilities that are in this job, they can find another job (Moore and Sales., 2005). On the other relation with age analysis job burnout negative and there was meaningful. These results agree with with results of the investigations:Godarzi(2002), Maslach and et al(2003), Hogan and Mcknight(2007), Schepman(2008), Loonstra(2009).It seems that people older than due to the experience more work, more emotional bond and the organization, more interested in being job and more pleasure from being with students and intimate relations with them, they can better with problems caused by stress and come to work. With students are more friendly relations. For these reasons less fatigue and lag caused by work in their results in the amount of stress and ex articulation analysis to young teachers with less than that.

With the expected increase with age teachers, they have also increased and the relationship between age and variables investigation in connection with a pledge to service record and exhaustion organizational job, but the research findings as well as other research in this field are also very contradictory. In this research, about organizational commitment and teaching teachers not relation with that research results as consistent Henkin and Holliman(2009), Ozdemir(2005),Moore and Sahes(2005), and with the results did not fit :Hamidi and et al(2008). The relationship between teaching and teachers burn out analysis was not seen that these results agree with findings of the investigations: Tumkaya(2001),Ursua (2005), Brien and et al(2008) . With regard to the contradictory results that the relationship other characteristics of a person with the main variables research exists, it seems that stability in more positive relationship with a pledge to age and organizational relationship with its negative job exhaustion. Although we still do not know that in various research rating the scope of the Sunni and the record of service Problem behaviors has been how much. In the case that based on the basis of age and theoretical research record due to personal and educational experiences can cope with stress factors determination of effective. On the other hand, two characteristics that can be an organization and commitment to continuous commitment regarding intellectual or raise, with regard to this relationship with organizational commitment age was relatively weak and also with teaching relationship was observed.In this research between the organization commitment and "Sex teachers in this regard that there was no research results agree with Lampart and et al (2008), Henkin and Holliman(2009) .The relation between the organizational commitment with the status of teachers,relation negative and meaningful results agree with of the investigations: Garland and et al(2009). Observed between organizational commitment and education organization negative and significant relationship agree with of the investigations: Garland and et al(2009). Study of the relationship other variables like sex knowledge population, the status of married and level of education teachers with organizational commitment and job burnout too controversial. In the research between sex with job burnout and organizational commitment teachers relationship was not significant and agree with of the investigations: Maslach(2001),Hogan(2007),Griffin(2005), Ozdemir (2008), Loonstra (2009). Librates seemed to be that women are employed because responsible for ensuring the simultaneous job and family ex articulation analysis more experienced and even their commitment of more than men Perhaps flexibility and more women in the organization of the relations between the char pie.

The amount of negative relationship Education teachers with organizational commitment and positive relationship with burn out in this research job not only more than the amount of the main variable relations with other characteristics of the individual, but with the principles of the existing theoretical in this field. In general educated men if they fail in the school abilities and learned to use their social status or from the perspective of others may be considered in spite of having more professional commitment of their organizational commitment will be reduced. And contrary to the exhaustion more job experience. This theme, to increase the level of education teachers of the various education is very important, because the education and training growth in the field educational facilities are very good teachers has, but it is necessary in the fields of stimulation and preserver occupational education teachers and their retention programs. Although the present research on the case with the results Kim van mo (1991),Asuman(2004), Hogan(2007) . was completely consistent. it should be reminded that the conditions of other schools educational organizations like university education and training centers and abroad is different.

In organizations like the education organization that is very important role in the training of human society a play; this issue is very important. This organization can be affected by the exhaustion many job commitment and teachers. This point, we should not forget that the education organization in smaller units to School Name also played a very important role. As active environment, gay and lively in school, Dawlatshah and lively gay teacher. participation in decision-making activities, the management style, salary and benefits of suitable and issues such as this can be on the amount of commitment to the working teachers and school and put it to influence their interest in education, teaching, and work to 
overshadow, so in order to balance the needs and demands and to prevent the exhaustion teachers have a job in the education system and teacher teaching coordination.

\section{References}

Ashrafi, R, Ahmadi, H, Mehrmand, A, GHolamiyan, A, Azizinnezhad, B .,2010. Investigate the relationship organizational commitment and school teachers' job burnout of city of mahabad, Journal of Psychology University of Tabriz, 5(18): 1-29.

Moien Parsa,K, Nazem,F,2010. the relationship Enterpreneur and organizational commitment with job burnout, Journal of Psychology Industrial - Organizational , 1(3):7-17.

Hamidi, M, Hosseini, E, Jahandideh, M.A ., 2007, The relationship between Leadership Style manegers who want to evolution and action with Organizational commitment in physical education experts fars province, Research on sport sciences, 3(5):13-22.

Hamidi, M ., 2003, The relationship Between Organizational Structure and effectiveness and Organizational commitment in headquarters areas Organizational countery sporting Phd Thesis University of Tehran.

Ramzaninezhad. R, Pour soltani, H, Hossininia. R ., 2009, The relationship school climate and burnout of physical educators in school teachers' city of Rasht, Journal of sport management,1: 225-235.

Seyed Gharaa-ainee, Kh, Seyedabbaaszadeh, M ., 2009, The relationship Between the Leadership Styles Of the High School Principals and Teachers Occupational Wear Down,Quarterly Journal Of Education, 25(1): 109-132.

Sabaghiyanerad, L, Toondnevis,F ., 2007, The relationship Between the organizational commitment and job burnoutgeneral physical education masters, Research on sport sciences, 10: 89-103.

Godarzi, M, Keshtidar, M ., 2002, The relationship Between individual particulars with manegers job burnout physical education and non physical education faculty and manegers university high instruction country, Journal of harakat , 13: 45-53.

Eric, G, Lampart, Nancy L,Hogan, Shanhe jiang., 2008, Exploring Antecedents of Five Type of Organizational Commitment Among Correctional Staff: It Matters what you Measure, 19(4): 446-490, www.sage.com.

Allan B,Henkin, Stephanie L, Holliman., 2009 .Urban Teacher Commitment, Exploring Associations With Organizational Conflict, Support for Innovation and participation, 44(2): 160-180. www.sage.com.

Asuman, D, Oylum Akkus C ., 2004 .The Relationship between Primary School Teachers Burnout and Some of Their Demografic Variables, 3(30): 55-60.

Andre, Brouwers, Welko, Tomic ., 1999,Teacher Burnout Perceived Self Efficancy in Classroom manegment, and Student Disruptive Behaviour in Secondary Education, Journal of Curriculum and Teaching, 14( 2): 7-26.

Bell- Roundtree, Carolyn V ., 2004 .Does Manager Behavior influence Khowledge Worker job Satisfaction and Organizational Commitment Attitude? Avalidation of Kovzes and Posners Transformational Leadership Theory,Dissertation of phd in organizational Psychology University of Albama in Huntsville 14,36-45.

Bert, Loonstra, Andre, Brouwers, Welko, Tomic ., 2009, Feelings of existential fulfillment and burnout among secondary school Teachers, 25(2009): 752-757, www.elsevier.com.

chuo, s .,2003, A Study of relationship Between organizational Commitment and Burnout Dissertation of PhD in organizational Psychology .21(6): 65-90.

Christin, Maslach, Wilmar, B, Schaufeli, Michael, p, Leiter, 2001 .Job Burn out ., Annual Reviews Psychology Downloaded by J. ar. Journals. Annual Review, 52,397-422.

Cheek, J, R, Bradley, L, J, Parr, G,Lan,W ., 2003 , Using Music Therapy Techniques To Treat Teacher Burnout, Journal of Mental Health Counseling, 25, 204-218.

Friedman,I,A ., 2000, Burnout Shattered Dreams of Impeccable Professional Performance, Journal of clinical Psychology, 56(9): 595606.

Garland, B, E .McCarty, W, P, Zhao R ., 2009, Job Satisfaction and organizational commitment in Prisons. Journal of Criminal Justice and behavior, 36(2):163-183.www.sage.com.

Griffin, MI, Hepburn, Jr ., 2005,Side-bets and Reciprocity Determinants of Organizational Commitment among Cirrectional Officers, Journal of Criminal Justice, 33, 611-625.

Hervelto, Moreira ., 1995, Physical Education Teachers and Job commitment: A Preliminary Analysis, European Physical Education Review 1(2): 122-138.

Heley.Gr ., 2003 .The relationship Between Burnout and organizational Commitment in Academic oncologists Dissertation of Dba, Nova, Southeastern University. 74(12): 36-51.

Han, K ., 2007 .Motivation and Commitment of Volunteer in A Marathon Running Event, PhD Thesis, The Florida State University, College Of Education.

Kim- Wan Mo ., 1991, Teacher Burnout, Relationship with Stress Personality, and Social support. Uhk Education Journal 19(1): 3-11.

Lakshmi, Ramarajan, Sigal G, Barsade ., 2006, The influence of Organizational Respect on Burnout in The Human Services, 19(10): 132.

Moore, E, Sales, A ., 2005, Organizational commitment as a predictor of Staff Working Alliances With Juvenile Offenders, Correction Compendium, 30(6,7): 33-35

Mathew, B, Shepherd, J., 2002, Dimensionality of cook and Walls (1980), British Organizational Commitment Seal Revisited, Journal of Occupational and organizational psychology, 75(3): 369-375.

Nor din, Abd, Razak, John P. Keeves., 2009, Teacher commitment, International Handbook of Research on Teachers and teaching, 56, 
343-360 .

Naomi, Fejgin, Rachel, Talmor, Ilana Erlich ., 2005 ,Inclusion and Burnout in Physical Education , Journal of European Physical Education Review, www.sage.com.11(1) : 29-50.

ORo, L. B and Ursua, M. P ., 2005, Teacher Irrational Beliefs and Their Relation With Educational Un easiness Clinica,Y, Salud,16, 4564.

Patrick, O'Brien, Richard Godard, Mary, Keeffe., 2008, Burnout Confirmed as a Viable Explanation for Beginning Teacher, 56(7) :1-20.

Pandey, R and Tripathis ., 2001, Occupational Stress and Burnout in Engineering College Teachers, Journal of the Indian Academy of Applied Psychology, 27, 67-73.

Lance, Hogan. Mark A. Mcknight ., 2007, Exploring Burnout among University Online Instructors: An initial Investigation, 10(2): 116-124, www.elsevier.com .

Stephen B. Schepman, Michael A. Zarate ., 2008,The Relationship between Burnout, Negative Affectivity and Organizational Citizenship Behavior and organizational commitment for Human services employees, 30(1341): 437-442.

Shanthi, Srinivas .,1994, Organizational Commitment and job Burnout among Employees of non-Profit Organizations, 32, 1-12.

Sabanci, Ali ., 2009, The Effect of primary school Teachers Burnout on organizational Health, 1,195-205, www.elsevier.com.

Tay, R, Dee, Alan B, Henkin, Carole, A, Singleton .,2006, Organizational commitment of Teachers in urban schools, 4(6): 603-627.

Tumkaya, S ., 2001, Burnout of Primary School Teachers with Different Level of Locus of Control, Turkish Psychological Counseling and Guidance Journal, 2(15): 29-40.

Yalcin, Ozdemir ., 2008, The Role of Classroom management Efficacy in Predicting Teacher Burnout International, Journal of Social Sciences, 2(4): 257-263. 